\title{
BMJ Open How does work disability of patients with MS develop before and after diagnosis? A nationwide cohort study with a reference group
}

\author{
Hanna Gyllensten, ${ }^{1,2}$ Michael Wiberg, ${ }^{1,3}$ Kristina Alexanderson, ${ }^{1}$ Jan Hillert, ${ }^{1}$ \\ Petter Tinghög ${ }^{1,4}$
}

To cite: Gyllensten $\mathrm{H}$, Wiberg M, Alexanderson K, et al. How does work disability of patients with MS develop before and after diagnosis? A nationwide cohort study with a reference group. BMJ Open 2016;6: e012731. doi:10.1136/ bmjopen-2016-012731

- Prepublication history for this paper is available online. To view these files please visit the journal online (http://dx.doi.org/10.1136/ bmjopen-2016-012731).

Received 20 May 2016 Revised 24 August 2016 Accepted 3 October 2016

\section{CrossMark}

For numbered affiliations see end of article.

Correspondence to Dr Hanna Gyllensten; hanna. gyllensten@ki.se

\section{ABSTRACT}

Objectives: We compared work disability of patients with multiple sclerosis (MS) from 5 years before with 5 years after diagnosis, with that of matched controls, and analysed whether progression in work disability among patients with MS was associated with sociodemography.

Design: Population-based cohort study.

Setting: The adult Swedish general population.

Participants: Residents aged 24-57 diagnosed with MS ( $n=3685)$ in 2003-2006 and 18425 matched controls without MS.

Primary and secondary outcome measures: Annual net days of sickness absence (SA) and disability pension (DP), used as a proxy for work disability, followed from 5 years before to 5 years after diagnosis (ie, $T-5-T+5$ ). For patients with MS, regression was used to identify sociodemographic factors related to progression in work disability.

Results: Work disability of patients with MS increased gradually between $T-5$ and $T-1$ (mean: $46-82$ days) followed by a sharp increase ( $T+1,142$ days), after which only a marginal increase was observed ( $T+5,149$ days). The matched controls had less work disability, slightly increasing during the period to a maximum of $\sim 40$ days. Men with MS had a sharper increase in work disability before diagnosis. High educational level was associated with less progression in work disability before and around diagnosis.

Conclusions: Patients with MS had more work disability days also 5 years before diagnosis. Several sociodemographic variables were associated with the absolute level and the progression in SA and DP.

\section{INTRODUCTION}

Multiple sclerosis (MS) is a progressive disorder often leading to substantial disability and high societal costs. ${ }^{12}$ MS generally starts during the most productive period of life when individuals usually are active on the labour market. However, it has been suggested that the work participation is altered

\section{Strengths and limitations of this study}

- The main strengths of this study includes the population-based design, use of nationwide registers with high completeness and validity, and a large cohort of patients with MS, thus enabling analyses of sociodemography on a nationwide scale.

- The main limitation to the study was the lack of clinical data on MS onset and diagnosis, but identifying year of diagnosis on first year with an MS diagnosis identified through the registers. This may result in individuals with a previous MS history (before the registers were available) being categorised as new patients with MS.

- To ensure proper follow-up of SA and DP, the study population had to be limited by age. Thus, patients with MS diagnosed in adolescence or as young adults were not included.

among patients with MS up to 8 years before diagnosis. ${ }^{3}$ A high rate of patients with MS also change employment position, reduce working hours or leave the workforce prematurely, ${ }^{4}$ including sickness absence (SA) and disability pension (DP). DP has been reported to be significantly increased already 5 years after onset of MS, compared with controls from the general population. ${ }^{5}$ Unemployment, or being outside the workforce, irrespectively of reason thereof, is very common among patients with MS. ${ }^{6-9}$

However, knowledge about how work disability of patients with MS develops over time and whether sociodemographic factors influence this development is still scarce. In particular, there is a lack of longitudinal studies based on large population-based samples. However, in countries with mandatory sickness insurance systems covering all residents, registered SA and DP can potentially be used as a proxy measure for work disability. A 
relapsing remitting disease course, higher educational level and light physical work has been suggested as predictors of longer time to DP. ${ }^{10}$ Moreover, one study identified sociodemographic factors associated with trajectories of SA and DP in patients with $\mathrm{MS},{ }^{11}$ although lack of a control group hindered comparisons with patterns in the general population.

In this study, we used Swedish nationwide register data on SA and DP to compare work disability among patients with MS from 5 years before to 5 years after diagnosis, with that of matched controls. Furthermore, we analysed if progression in work disability among patients with MS was associated with sociodemography.

\section{METHODS}

\section{Study population and materials}

This study consists of 3685 individuals diagnosed with MS between 2003 and 2006 and 18425 propensity scorematched controls. All individuals were living in Sweden on the 31 December 2004. Register data included population-based data linked by personal identification numbers from; the Longitudinal integration database for health insurance and labour market studies (LISA) from Statistics Sweden (used for identifying the cohorts and for sociodemographics), the National Patient Register $^{12}$ from the National Board of Health and Welfare (including information about specialised outpatient and inpatient care), and SA and DP registered at the National Social Insurance Agency. Approval for the project was received from the Regional Ethical Review Board in Stockholm (2007/762-31) and it conformed to the Declaration of Helsinki. ${ }^{13}$

The study population was attained in two steps. First, based on the year of MS diagnosis, patients with MS were categorised into four panels: 2003-2006. The year of MS diagnosis was defined as the first time the individual received MS as primary or secondary diagnosis code (ICD-9: 340, ICD-10; G35) in the inpatient care (available since 1987) or specialised outpatient care (since 2001). Included individuals were in ages 24-59 at year of diagnosis to ensure information for 5 years before and after diagnosis could be included.

Second, five controls from the general population (without previous MS diagnosis or MS diagnosis during the studied period) were identified using propensity score matching, by greedy matching without replacement. ${ }^{14}$ Propensity scores for the matching were generated by logistic regression with MS (yes/no) as dependent variable and independent variables measured in the year of diagnosis being; age, sex, cohabiting/marital status, living with children, place of birth, type of living area geographic region and educational level. The procedure was repeated for each panel (ie, each year of diagnosis). Individuals that were matched to patient with MS in panel 2003 were not available for matching in panels 2004-2006, and so on. After matching, balance scores were used to ensure $\leq 10 \%$ residual imbalance ${ }^{14}$ in independent variables between patients with MS and controls.

All individuals were followed up from 5 years before $(\mathrm{T}-5)$ to 5 years after $(\mathrm{T}+5)$ date of diagnosis, using annual information on SA, DP and sociodemographics: educational level, living with children (age $<19$ ), cohabiting/marital status, type of living area (based on population density), geographical regions. ${ }^{15} 16$ Additionally, sex, age and country of birth were attained at the year of diagnosis.

\section{Outcome measure and the social insurance system}

Our proxy measure for work disability was the annual number of net days of SA and DP combined (hereafter SA/DP) irrespective of SA or DP diagnoses. Studying only one of the systems and/or gross days of absence could give misleading results in terms of the individuals' work disability, as individuals may be on part-time SA and DP simultaneously and that individuals on full-time $\mathrm{DP}$ are not eligible for $\mathrm{SA} .{ }^{17}$ In Sweden, $\sim 65 \%$ of patients with MS had any SA or DP during 2010 and of these $12 \%$ had part-time use of both benefits during the same year (unpublished results).

In Sweden, all residents of working ages who have income from work or unemployment benefits are entitled to sickness benefits if they, due to disease or injury, are unable to work or prevented from job searching. During the first period (often 14 days) of SA, employed individuals are in most cases compensated by their employer, with the exception of a first uncompensated day. We therefore lack data on such short SA. All people with a disease or injury leading to long-term or permanent work disability can be granted full-time or part-time DP from the age of 19. Our measure of work disability thus do not discriminate based on the reason for receiving SA and/or DP, but is distinguished from other types of disability and other causes for decreased work participation.

\section{Analyses}

Mean annual SA/DP days and differences in mean days between patients with MS and controls, were calculated, overall and stratified by sociodemographic variables, at $\mathrm{T}$ $-5, \mathrm{~T}-1, \mathrm{~T} 0, \mathrm{~T}+1$ and $\mathrm{T}+5$. The differences were tested for statistical significance $(\alpha=0.05)$ using two-tailed t-tests with unequal variances.

Ordinary least squares (OLS) regression analyses with robust SDs were performed, for the patients with MS without controls, to gain insight on how sociodemographic variables affect the individual progression of SA/DP among patients with MS. The dependent variable was the difference in work disability, measured as SA/DP days, between two time points for each individual. Three linear regressions were performed: (1) $\mathrm{T}-1$ vs $\mathrm{T}-5$, (2) $\mathrm{T}+1$ vs $\mathrm{T}-1$ and (3) $\mathrm{T}+5$ vs $\mathrm{T}+1$. 
Table 1 Frequencies and proportions of patients with MS and controls at year of MS diagnosis, stratified by sociodemographics

\begin{tabular}{|c|c|c|c|c|}
\hline & \multicolumn{2}{|l|}{ MS } & \multicolumn{2}{|c|}{ Controls } \\
\hline & $\mathbf{N}$ & $\begin{array}{l}\text { Per } \\
\text { cent }\end{array}$ & $\mathbf{n}$ & $\begin{array}{l}\text { Per } \\
\text { cent }\end{array}$ \\
\hline \multicolumn{5}{|l|}{ Age groups } \\
\hline $24-34$ & 934 & 25.3 & 4383 & 23.8 \\
\hline $35-44$ & 1161 & 31.5 & 5952 & 32.3 \\
\hline 45-59 & 1590 & 43.1 & 8090 & 43.9 \\
\hline \multicolumn{5}{|l|}{ Sex } \\
\hline Men & 1114 & 30.2 & 5438 & 29.5 \\
\hline Women & 2571 & 69.8 & 12987 & 70.5 \\
\hline \multicolumn{5}{|l|}{ Born in Sweden* } \\
\hline Yes & 3303 & 89.6 & 16180 & 87.8 \\
\hline No & 382 & 10.4 & 2245 & 12.2 \\
\hline \multicolumn{5}{|l|}{ Married or cohabiting } \\
\hline Yes & 2060 & 55.9 & 10317 & 56.0 \\
\hline No & 1625 & 44.1 & 8108 & 44.0 \\
\hline \multicolumn{5}{|l|}{ Living with children } \\
\hline Yes & 1841 & 50.0 & 9161 & 49.7 \\
\hline No & 1844 & 50.0 & 9264 & 50.3 \\
\hline \multicolumn{5}{|l|}{ Educational level† } \\
\hline High school or less & 2307 & 62.6 & 11232 & 61.0 \\
\hline University & 1378 & 37.4 & 7193 & 39.0 \\
\hline \multicolumn{5}{|l|}{ Type of living area } \\
\hline Larger cities & 1404 & 38.1 & 6899 & 37.4 \\
\hline $\begin{array}{l}\text { Medium-sized } \\
\text { municipalities }\end{array}$ & 1289 & 35.0 & 6430 & 34.9 \\
\hline $\begin{array}{l}\text { Smaller } \\
\text { municipalities }\end{array}$ & 992 & 26.9 & 5096 & 27.7 \\
\hline \multicolumn{5}{|l|}{ Geographic region } \\
\hline East & 1483 & 40.2 & 7631 & 41.4 \\
\hline South/West & 1529 & 41.5 & 7104 & 38.6 \\
\hline North & 673 & 18.3 & 3690 & 20.0 \\
\hline \multicolumn{5}{|l|}{ Panel } \\
\hline 2003 & 1084 & 29.4 & 5420 & 29.4 \\
\hline 2004 & 956 & 25.9 & 4780 & 25.9 \\
\hline 2005 & 883 & 24.0 & 4415 & 24.0 \\
\hline 2006 & 762 & 20.7 & 3810 & 20.7 \\
\hline All & 3685 & 100.0 & 18425 & 100.0 \\
\hline
\end{tabular}

${ }^{*}$ The category not born in Sweden includes $<10$ individuals with missing country of birth.

†The category high school or less includes 156 individuals with missing educational level.

MS, multiple sclerosis.

\section{RESULTS}

Among the patients with MS, most were women (69.8\%) between ages 45 and $59(43.1 \%$ ) (table 1). The sociodemographic characteristics for the matched controls were almost identical to that observed among the patients with MS, with balance scores below 6\% (numbers not shown).

For the controls, mean SA/DP days slightly increased until the year of matching, thereafter stabilised around 40 days per year (figure 1). For the patients with MS, SA/DP days were increasing throughout the time period, but with varying rate of progression. The mean increase among patients with MS was 9 days per year in

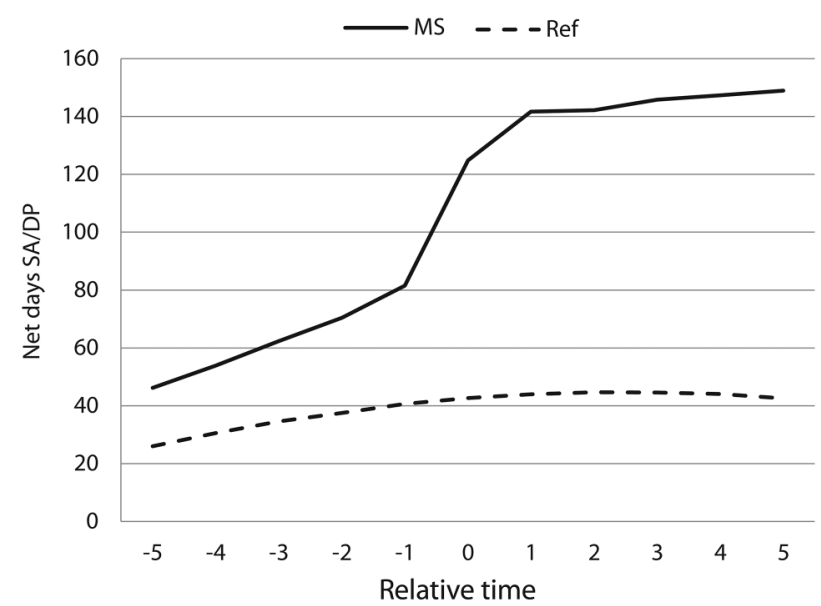

Figure 1 Annual net days with SA/DP per year, among patients with MS and controls, respectively, in relation to year of MS diagnoses (T0). DP, disability pension; MS, multiple sclerosis; SA, sickness absence.

the period $\mathrm{T}-5$ to $\mathrm{T}-1$ (from 46 to 82 days over 4 years), increased to 30 days per year in the period $\mathrm{T}-1$ to $\mathrm{T}+1$ and again decreased to $<2$ days per year in the period $T+1$ to $T+5$. In the period $T-5$ to $T-1$ there was almost a doubling of the number of days, from 46 to 82 davs (figure 1 ). The steepest increase over time was in the period around diagnosis $(\mathrm{T}-1$ to $\mathrm{T}+1)$, where the mean number of days changes from 82 to 142 days in 2 years. Thereafter $(\mathrm{T}+1$ to $+\mathrm{T} 5)$, the increase continued but with lower rate of change, to 149 days in $\mathrm{T}+5$.

Among patients with MS, SA was highest around the year of diagnosis (figure 2). However, DP increased with time, and thus the proportion of DP in relation to all $\mathrm{SA} / \mathrm{DP}$ decreased from $56 \%$ at $\mathrm{T}-5$ to $<50 \%$ at $\mathrm{T}+1$ and increased thereafter to $86 \%$ of SA/DP at $\mathrm{T}+5$.

Women with MS had more SA/DP days than men with MS throughout the entire period (table 2), and women with MS had, at all time points, higher mean SA/DP

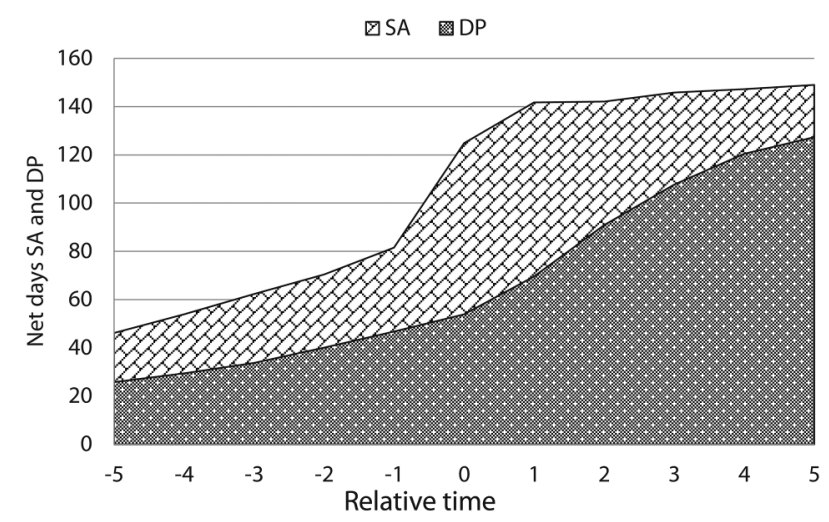

Figure 2 Mean number of net days per year with sickness absence (SA) and disability pension (DP), respectively, among patients with MS, five years before the year of MS diagnosis (T0) to five years after. DP, disability pension; MS, multiple sclerosis; SA, sickness absence. 
Table 2 Difference in mean number of net days of SA/DP between patients with MS and controls, stratified by sociodemographics

\begin{tabular}{|c|c|c|c|c|c|}
\hline \multirow[b]{2}{*}{ Variables } & \multicolumn{5}{|c|}{5 years before to 5 years after the year of diagnosis (T0) } \\
\hline & $\mathrm{T}-5$ & $\mathrm{~T}-1$ & T0 & $T+1$ & $T+5$ \\
\hline All & $20(46)$ & $41(82)$ & $82(125)$ & $98(142)$ & 106 (149) \\
\hline \multicolumn{6}{|l|}{ Age } \\
\hline 24-34 & $4(19)^{*}$ & $15(35)$ & $49(68)$ & $59(78)$ & $52(66)$ \\
\hline $35-44$ & $21(46)$ & $33(66)$ & 75 (109) & $92(125)$ & 79 (103) \\
\hline $45-59$ & $43(87)$ & $66(127)$ & $108(170)$ & $122(182)$ & $127(173)$ \\
\hline \multicolumn{6}{|l|}{ Sex } \\
\hline Male & $13(34)$ & $39(69)$ & $80(112)$ & $96(130)$ & $105(137)$ \\
\hline Women & $23(52)$ & $42(87)$ & $83(131)$ & 98 (147) & $107(154)$ \\
\hline \multicolumn{6}{|l|}{ Born in Sweden } \\
\hline Yes & $21(46)$ & $42(82)$ & $84(125)$ & $99(142)$ & $107(148)$ \\
\hline No & $14(45)$ & $30(76)$ & $71(120)$ & $90(143)$ & $106(162)$ \\
\hline \multicolumn{6}{|l|}{ Married or cohabiting } \\
\hline Yes & $23(45)$ & $42(76)$ & $85(121)$ & $99(135)$ & $104(136)$ \\
\hline No & $17(47)$ & $40(88)$ & 78 (130) & 96 (151) & $110(169)$ \\
\hline \multicolumn{6}{|l|}{ Living with children } \\
\hline Yes & $18(50)$ & $45(94)$ & $85(138)$ & $105(161)$ & $122(184)$ \\
\hline No & $22(43)$ & $37(69)$ & 79 (111) & $91(123)$ & $90(113)$ \\
\hline \multicolumn{6}{|l|}{ Education } \\
\hline High school or less & $23(56)$ & $49(102)$ & $95(151)$ & $111(170)$ & $120(178)$ \\
\hline University & $13(26)$ & $26(47)$ & $59(81)$ & $75(96)$ & $84(104)$ \\
\hline \multicolumn{6}{|l|}{ Type of living area } \\
\hline Larger cities & $23(54)$ & $48(97)$ & 98 (149) & $116(169)$ & $131(181)$ \\
\hline Medium-sized municipalities & $18(44)$ & $41(83)$ & 79 (124) & 97 (142) & $106(152)$ \\
\hline Smaller municipalities & $20(42)$ & $36(70)$ & $74(108)$ & 86 (122) & 89 (123) \\
\hline \multicolumn{6}{|l|}{ Geographic region } \\
\hline East & $18(41)$ & $37(73)$ & $74(111)$ & 92 (129) & 95 (131) \\
\hline South/West & $21(48)$ & $45(87)$ & $86(131)$ & $99(146)$ & $110(157)$ \\
\hline North & $23(53)$ & $40(89)$ & $91(142)$ & $108(160)$ & $122(170)$ \\
\hline
\end{tabular}

days compared with their matched controls than had men with MS. The difference by sex, of patients with MS compared with controls, was less pronounced from $\mathrm{T}-1$ an onwards. Individuals with university education had fewer days compared with those with lower level of education. Moreover, the difference between patients with MS and controls increased more with time for those with lower education ( $\mathrm{T}-5$ : 23 days, $\mathrm{T}=0$ : 95 days, $\mathrm{T}+5$ : 120 days) compared with those with higher education ( $\mathrm{T}-5$ : 13 days, $\mathrm{T}=0: 59$ days, $\mathrm{T}+5: 84$ days). The difference by age, between patients with MS and the controls, was larger among the older age groups, although the rate of progression was larger in younger patients. The two younger age categories decreased mean SA/DP days between $T+1$ and $T+5$ compared with controls.

During the time period before diagnosis $(\mathrm{T}-5$ to $\mathrm{T}$ -1 ), the increase in SA/DP days was higher for patients with MS in older ages compared with in younger individuals (age 24-34) $\quad\left(\beta_{35-44}=10.6, \quad \mathrm{p}<0.05 ; \quad \beta_{45-59}=22.9\right.$, $\mathrm{p}<0.05)$ also after adjusting for other variables using regression analysis (table 3). Patients with MS having university education had lower increase in SA/DP $(\beta=$
$-13.1, \mathrm{p}<0.05)$. The results when analysing the period around diagnosis (ie, the changes between $\mathrm{T}-1$ and $\mathrm{T}$ +1 ) were similar to the estimates for the first period; older patients with MS and those with lower education had steeper increase in number of days compared with the other groups. During the period after diagnosis $(\mathrm{T}+1$ to $\mathrm{T}+5)$, patients with MS in ages $45-59$ had higher increase in SA/DP over time, but education did not appear to be associated with change in SA/DP during that period.

\section{DISCUSSION}

In this register-based study of more than 3500 patients with MS, we found that they had higher work disability compared with matched controls already 5 years before MS diagnosis. Work disability of patients with MS increased gradually in the prediagnostic period followed by a sharp increase around the year of diagnosis, after which only a marginal increase was observed during the first 5 years after diagnosis. This contrasts to the progression in matched controls who had a lower initial work 
Table 3 Associations between sociodemography and change in number of net days with SA/DP among patients with MS, results from three linear regression models

\begin{tabular}{|c|c|c|c|}
\hline & $\begin{array}{l}\text { Period 1: diff (T-1 vs T-5) } \\
\text { Estimate (Cl 95\%) }\end{array}$ & $\begin{array}{l}\text { Period 2: diff (T+1 vs } \mathrm{T}-1) \\
\text { Estimate }(\mathrm{Cl} 95 \%)\end{array}$ & $\begin{array}{l}\text { Period 3: diff }(\mathrm{T}+5 \text { vs } \mathrm{T}+1) \\
\text { Estimate (Cl } 95 \%)\end{array}$ \\
\hline Intercept & $38.6(23.6 \text { to } 53.6)^{\star \star \star}$ & $62.8(43.6 \text { to } 82.1)^{\star \star \star}$ & $5.2(-13.3$ to 23.7$)$ \\
\hline \multicolumn{4}{|l|}{ Age (ref: 24-34) } \\
\hline $35-44$ & $10.6(2.8 \text { to } 18.3)^{\star \star \star}$ & $16.2(5.8 \text { to } 26.6)^{\star \star \star}$ & $7.0(-3.0$ to 17$)$ \\
\hline $45-59$ & $22.9(14.7 \text { to } 31.1)^{\star \star \star}$ & $14.1(4.6 \text { to } 23.7)^{\star \star \star}$ & $26.8(17.9 \text { to } 35.6)^{\star \star \star}$ \\
\hline \multicolumn{4}{|l|}{ Sex (ref: female) } \\
\hline Male & $-1.1(-8.1$ to 5.9$)$ & $0.4(-8.0$ to 8.9$)$ & $2.6(-5.0$ to 10.1$)$ \\
\hline \multicolumn{4}{|l|}{ Born in Sweden (ref: yes) } \\
\hline No & $-6.0(-17.7$ to 5.6$)$ & $-12.4(-26 \text { to } 1.1)^{\star}$ & $-12.4(-25.3 \text { to } 0.4)^{\star}$ \\
\hline \multicolumn{4}{|l|}{ Married or cohabiting (ref: no) } \\
\hline Yes & $0.3(-8.3$ to 8.8$)$ & $1.4(-8.0$ to 10.8$)$ & $3.1(-5.5$ to 11.6$)$ \\
\hline \multicolumn{4}{|l|}{ Living with children (ref: no) } \\
\hline Yes & $-0.7(-9.2$ to 7.8$)$ & $-3.8(-13.4$ to 5.7$)$ & $1.9(-6.5$ to 10.4$)$ \\
\hline \multicolumn{4}{|c|}{ Education (ref: High school of less) } \\
\hline University & $-13.1(-19.6 \text { to }-6.6)^{\star \star \star}$ & $-11.5(-19.5 \text { to }-3.6)^{\star \star \star}$ & $6.1(-1.1 \text { to } 13.3)^{*}$ \\
\hline \multicolumn{4}{|c|}{ Type of living area (ref: Larger cities) } \\
\hline Medium-sized municipalities & $9.9(2.2 \text { to } 17.5)^{\star \star}$ & $4.4(-4.7$ to 13.5$)$ & $5.6(-2.8$ to 13.9$)$ \\
\hline Smaller municipalities & $9.7(0.6 \text { to } 18.8)^{\star \star}$ & $11.2(0.3 \text { to } 22.2)^{\star \star}$ & $7.2(-2.3$ to 16.6$)$ \\
\hline \multicolumn{4}{|l|}{ Geographical region (ref: east) } \\
\hline South/West & $2.6(-4.4$ to 9.6$)$ & $0.3(-8.2$ to 8.7$)$ & $5.2(-2.5$ to 12.8$)$ \\
\hline North & $-4.2(-14.3$ to 5.9$)$ & $6.2(-6.1$ to 18.5$)$ & $0.6(-10.1$ to 11.3$)$ \\
\hline \multicolumn{4}{|l|}{ Panel (ref: 2003) $\dagger$} \\
\hline 2004 & $-5.8(-14.5$ to 2.9$)$ & $-3.4(-13.8$ to 7.0$)$ & $-13.3(-22.6 \text { to }-4.0)^{\star \star \star}$ \\
\hline 2005 & $-11.6(-20.3 \text { to }-2.8)^{\star \star \star}$ & $-2.7(-13.1$ to 7.8$)$ & $-14.9(-24.3 \text { to }-5.4)^{\star \star \star}$ \\
\hline 2006 & $-19.3(-28.2 \text { to }-10.4)^{\star \star \star *}$ & $-3.6(-14.6$ to 7.5$)$ & $-16.7(-26.2 \text { to }-7.2)^{\star \star \star}$ \\
\hline $\mathbf{n}$ & 3608 & 3652 & 3587 \\
\hline
\end{tabular}

disability that increased slightly until year of matching and after that remained quite stable. The increase in work disability among patients with MS, measured as mean SA/DP days, was similar in all investigated sociodemographic subcategories, although slightly more pronounced in those of older age, lower education and some categories of living areas. However, sociodemographics appeared to be less associated with the progression of work disability of patients with MS in the years after diagnosis.

The strengths of the study include the populationbased design, using several nationwide registers with high completeness and high validity, ${ }^{12}{ }^{18}$ together with a large cohort of patients with MS; which enabled analyses of sociodemography on a nationwide scale. Our study also has limitations: We assume a first registered hospitalisation or outpatient visit with MS diagnosis in 2003-2006 to represent date of diagnosis. Due to lack of information on outpatient care before 2001 this is, however, uncertain - that is, some might not have had any inpatient or outpatient care contact in those years, although that, due to care regimes, is very unlikely. However, we assume that most patients with MS have healthcare contacts at least once during a 2-year period (2001-2002). We also had no information on actual onset of disease. Thus, we presented data by panel year and included panel as a variable in the regression analysis to account for potential differences in, for example, time from onset to diagnosis between the four panels. Moreover, our analyses using SA and DP data from several years before MS diagnosis does affect the age distribution in our study population, as those diagnosed with MS during early ages were excluded. The study should be viewed as explorative, no in-depth analysis of relative importance, interactions or causal pathways of specific sociodemographic variables were attempted, such as associations with local labour market conditions or if our findings represents inequalities that needs to be addressed.

Although the causes of work disability were not analysed in the study, we compared the results with that of matched controls to indicate how much of the work disability that could be assumed to be due to the MS disease. In this study, we used propensity score matching to identify a control group similar to patients with MS at year of diagnosis. Propensity score matching is often used in studies estimating the attributable effect of treatment in observational studies, ${ }^{19}{ }^{20}$ but has also been used in exploring the effects of disability, road injuries $^{21-24}$ and disease. ${ }^{25}$ In such studies, the disease onset or accident is analysed as if it was an initiated treatment, comparing individuals matched on pre-event characteristics. Most of our matching criteria were time 
independent, thus fulfilling these demands for pre-event criteria. However, our findings that SA/DP days was higher already at least 5 years before MS diagnosis indicate that matching should potentially be made on a time point before diagnosis, particularly if matching criteria is affected by the disease or symptoms.

The analysis of sickness benefits in a specific country may appear less relevant in other settings. However, these results, using data on all individuals diagnosed with MS during the studied period, and complete SA/DP data from an almost universal sickness benefits system, have more general implications in relation to work disability, symptoms resulting in short-term (SA) and long-term (DP) disability, and the clinical course of the MS disease. The use of SA/DP in this manner can also be of relevance to other diseases where it has been suggested that the symptoms may start prior to assumed onset. However, to operationalise work disability in this way, using data on sickness benefits, is not without problem, as the benefits scheme and policy may change over time. This may have an impact on the validity of our study, although we expect that such alterations have had a similar impact on patients with MS and the matched control groups.

Although work disability was more common in some population groups with MS, not all patients with MS had SA/DP. This is in line with previous findings that $25 \%$ of all patients with MS were working essentially full-time, and $21 \%$ had no external financial support. ${ }^{26}$ In Sweden, $62 \%$ of the patients with MS were on DP in 2005 , while $37 \%$ of the remaining had longer SA spells during a 12-month study period. ${ }^{27}$ However, Björkenstam and colleagues found ${ }^{11}$ that sociodemographic factors in themselves poorly predicted the trajectories of SA/DP days among patients with MS in Sweden, and that previous SA/DP was a better predictor of postdiagnosis SA/DP trajectories than the sociodemographic factors. ${ }^{11}$ Older age and educational level have previously been found associated with postdiagnosis SA/DP trajectories, which is in accordance with our results. As the source populations in the publication by Björkenstam et $a l^{11}$ and this current analysis were very similar, this was expected. However, we did not find the same ${ }^{11}$ association of sex and country of birth to work disability. This warrants further analyses as to the association between overall trajectories of SA/DP and the absolute levels and progression at different time points.

The initial course of MS disease is unpredictable and may affect individuals very differently. In majority of patients with MS, the disease begins with a relapsing course followed after several years by a progressive phase ${ }^{28}$ but it is possible that some phenotypes of MS may delay diagnosis more than others. We found a high rate of SA/DP days already 5 years prior the year of MS diagnosis, and a previous study ${ }^{3}$ found lower work participation already 8 years before diagnosis. Our results are also in line with a previous study reporting increased DP already 5 years after MS onset. ${ }^{5}$ Thus, it may be suggested that the clinical course of the disease with regards to work disability starts before the diagnosis, and possibly even before the assumed disease onset. It appears that the average time from onset to diagnosis was 4-5 years during our study period (unpublished results from the Swedish National Multiple Sclerosis Register). Thus, more studies are warranted to examine work disability in relation to disease onset and a potential prodromal phase of the MS disease. ${ }^{29}$ The trend towards higher SA/DP already in the youngest age group makes it less likely that the increase was the result of delayed time to diagnosis among older patients with MS compared with younger. Moreover, it indicates that MS may be diagnosed earlier during the disease course among some patients in the future, potentially before todays assumed disease onset. This issue needs to be further explored, to identify methods for finding persons developing early symptoms, to ensure that work disability due to the MS disease is covered for by the sickness benefits scheme, and with regards to potentially earlier treatment initiation.

In register-based research, there is a need for measurements of disease progression collected routinely in administrative data, which preferably includes physical and mental aspects. Expanded Disability Status Scale (EDSS) has been the standard and dominating measurement for investigating MS progression. EDSS predominantly measures motor functions and has been used to, for example, find that time from symptomatic onset until reaching EDSS 6 (equivalent of requiring a cane to walk) range between 15 and 25 years. ${ }^{30}$ However, EDSS is not collected among people without at least suspicion of MS, and it is likely that the scale is filled in more frequently by patients with MS having more frequent healthcare encounters (eg, due to problems in the treatment or worse symptoms). We thus used information on financially compensated reduced work capacity from the sickness insurance system as a proxy for disease progression. However, the identified apparent inequalities by sociodemographic characteristics may be underestimations, since the different levels of SA/DP may provide a ceiling effect to those with high SA/DP use already at T -5 . Moreover, there is a need to better understand how the design of social insurance systems (eg, sickness insurance) interacts with eg labour markets for these types of outcomes. For example, the possibility of part-time absence in sickness insurance policy could potentially be of great importance. Thus, studying work disability using the proxy SA/DP may enhance the understanding of consequences of living with chronic disease, and give new insights into the effects of sickness insurance policy in a society.

\section{CONCLUSION}

Our results indicate that patients with MS have more work disability also 5 years before diagnosis. We also observed several sociodemographic variables associated 
with the absolute level and the progression in work disability, that is, higher age, smaller living areas and a low level of education, in particular during the period before and around diagnosis. Thereafter, it appears as the situation stabilised which resulted in that sociodemographic factors only marginally influenced the progression of work disability among patients with MS.

\section{Author affiliations}

${ }^{1}$ Department of Clinical Neuroscience, Karolinska Institutet, SE-171 77 Stockholm, Sweden

${ }^{2}$ Centre for Person-centred Care (GPCC), and Institute of Health and Care Sciences, Sahlgrenska Academy, University of Gothenburg, Gothenburg, Sweden

${ }^{3}$ Department of Analysis and Prognosis, Swedish Social Insurance Agency, Stockholm, Sweden

${ }^{4}$ Department of Public Health and Medicine, Red Cross University College, Stockholm, Sweden

Contributors PT was the principal investigator. MW did the analyses. HG, MW and PT drafted the manuscript. HG, MW, KA, JH and PT contributed to the study design, interpretation of results and commented on the draft and final version of the manuscript. All authors had full access to all data. PT is the guarantor of the study.

Funding This work was supported by Biogen and by the Swedish Research Council for Health, Working Life and Welfare (2007-1762).

Competing interests HG, PT and MW were funded by Biogen. KA has received project grant from Biogen and several Swedish research councils. $\mathrm{JH}$ received honoraria for serving on advisory boards for Biogen and Novartis and speaker's fees from Biogen, Merck-Serono, Bayer-Schering, Teva and Sanofi-Aventis. He has served as P.I. for projects sponsored by, or received unrestricted research support from, Biogen, Merck-Serono, TEVA, Novartis and Bayer-Schering. His MS research is funded by the Swedish Research Council. Biogen reviewed and provided feedback on the paper to the authors. The authors had full editorial control of the paper, and provided their final approval of all content.

Ethics approval Approval for the project was received from the Regional Ethical Review Board in Stockholm (2007/762-31). According to Swedish laws and regulations related to ethical vetting the study did not required informed consent of participants because of the retrospective study design which did not affect the healthcare of included patients. All the analysed materials were retrieved from national registers collected for other purposes. Personal identity numbers and names were unavailable to the research group, and data was analysed anonymously.

Provenance and peer review Not commissioned; externally peer reviewed.

Data sharing statement No additional data are available.

Open Access This is an Open Access article distributed in accordance with the Creative Commons Attribution Non Commercial (CC BY-NC 4.0) license, which permits others to distribute, remix, adapt, build upon this work noncommercially, and license their derivative works on different terms, provided the original work is properly cited and the use is non-commercial. See: http:// creativecommons.org/licenses/by-nc/4.0/

\section{REFERENCES}

1. Busche K, Fisk J, Murray T, et al. Short term predictors of unemployment in multiple sclerosis patients. Can J Neurol Sci 2003;30:137-42.

2. Strober LB, Christodoulou C, Benedict $\mathrm{RH}$, et al. Unemployment in multiple sclerosis: the contribution of personality and disease. Mult Scler 2012;18:647-53.

3. Jennum P, Wanscher B, Frederiksen J, et al. The socioeconomic consequences of multiple sclerosis: a controlled national study. Eur Neuropsychopharmacol 2012;22:36-43.
4. Moore $\mathrm{P}$, Harding KE, Clarkson $\mathrm{H}$, et al. Demographic and clinical factors associated with changes in employment in multiple sclerosis. Mult Scler 2013;19:1647-54.

5. Pfleger $\mathrm{CCH}$, Flachs EM, Koch-Henriksen N. Social consequences of multiple sclerosis (1): early pension and temporary unemployment -a historical prospective cohort study. Mult Scler 2010;16:121-6.

6. Grønning M, Hannisdal E, Mellgren SI. Multivariate analyses of factors associated with unemployment in people with multiple sclerosis. J Neurol Neurosurg Psychiatry 1990;53:388-90.

7. Julian LJ, Vella L, Vollmer T, et al. Employment in multiple sclerosis J Neurol 2008;255:1354-60.

8. Krause I, Kern S, Horntrich A, et al. Employment status in multiple sclerosis: impact of disease-specific and non-disease-specific factors. Mult Scler 2013;19:1792-9.

9. LaRocca N, Kalb R, Scheinberg $\mathrm{L}$, et al. Factors associated with unemployment of patients with multiple sclerosis. J Chronic Dis 1985;38:203-10.

10. Glad SB, Nyland $\mathrm{H}$, Aarseth $\mathrm{JH}$, et al. How long can you keep working with benign multiple sclerosis? J Neurol Neurosurg Psychiatr 2011;82:78-82.

11. Björkenstam $\mathrm{C}$, Alexanderson $\mathrm{K}$, Wiberg $\mathrm{M}$, et al. Heterogeneity of sickness absence and disability pension trajectories among individuals with MS. Mult Scler 2015;1:2055217315595638

12. Ludvigsson JF, Andersson E, Ekbom A, et al. External review and validation of the Swedish national inpatient register. BMC Public Health 2011;11:450.

13. Association WM. World Medical Association Declaration of Helsinki: ethical principles for medical research involving human subjects. JAMA 2013;310:2191.

14. Parsons LS, ed. Performing a 1: $\mathrm{N}$ case-control match on propensity score. Proceedings of the 29th SAS Users Group International (SUGI) conference; 2004

15. Rikets indelningar: årsbok över regionala indelningar med koder, postadresser, telefonnummer m m 2003 [Country classifications: yearbook of regional classifications with codes, postal addresses phone numbers etc. 2003]. Stockholm: Statistics Sweden 2003. ISBN: 91-618-1147-5.

16. SCB. Background Facts, Labour and Education Statistics 2011:4, Integrated database for labour market research. Report: Statistics Sweden. Report No.: 1654-465X (online), 2011.

17. Försäkringskassan. Social insurance in figures 2014. Swedish Social Insurance Agency Stockholm, Sweden, 2014. ISBN: 978-917500-380-1.

18. Kamper-Jørgensen F, Arber S, Berkman L, et al. Part 3: International evaluation of Swedish public health research. Scand J Public Health 2005;33(65 Suppl):46-84.

19. Austin PC. An introduction to propensity score methods for reducing the effects of confounding in observational studies. Multivariate Behav Res 2011;46:399-424.

20. Groenwold R, Hak E, Hoes A. Quantitative assessment of unobserved confounding is mandatory in nonrandomized intervention studies. J Clin Epidemiol 2009;62:22-8.

21. Dano AM. Road injuries and long-run effects on income and employment. Health Econ 2005;14:955-70.

22. García Gómez P, López Nicolás A. Health shocks, employment and income in the Spanish labour market. Health Econ 2006;15:997-1009.

23. Lechner M, Vazquez-Alvarez R. The effect of disability on labour market outcomes in Germany. Appl Econ 2011;43:389-412.

24. Polidano $\mathrm{C}, \mathrm{Vu} \mathrm{H}$. Differential labour market impacts from disability onset. Health Econ 2015;24:302-17.

25. Roberts RR, Scott RD II, Hota B, et al. Costs attributable to healthcare-acquired infection in hospitalized adults and a comparison of economic methods. Med Care 2010;48:1026-35.

26. McDonnell G, Hawkins S. An assessment of the spectrum of disability and handicap in multiple sclerosis: a population-based study. Mult Scler 2001;7:111-17.

27. Tinghög $P$, Hillert J, Kjeldgård L, et al. High prevalence of sickness absence and disability pension among multiple sclerosis patients: a nationwide population-based study. Mult Scler 2013;19:1923-30.

28. Lassmann H, Brück W, Lucchinetti CF. The immunopathology of multiple sclerosis: an overview. Brain Pathol 2007;17:210-18.

29. Ramagopalan SV, Dobson R, Meier UC, et al. Multiple sclerosis: risk factors, prodromes, and potential causal pathways. Lancet Neurol 2010;9:727-39.

30. Confavreux C, Vukusic S, Moreau T, et al. Relapses and progression of disability in multiple sclerosis. $N \mathrm{Engl} J \mathrm{Med}$ 2000;343:1430-8. 